\title{
Ambiguous Status of Single Mothers in India
}

\author{
Pradeep Kumar Panda* \\ Doctoral Scholar (Economics), School of Social Sciences, IGNOU, New Delhi
}

*Corresponding author: Pradeep Kumar Panda, Andhra Pradesh Industrial and Technical Consultancy Organisation Limited, Hyderabad, Telangana, India

Submission: 祭 August 21, 2017; Published: 每 May 17, 2018

\section{Introduction}

The number of single mothers has grown phenomenally all across the world in the last three decades, in large part as a result of the growing number of children born outside of marriage. Unfortunately there is no official information on number of single mothers residing in India. However few studies clearly illustrate that this is a rising phenomenon in India.

Government of India should collect and publish data on number of single mothers in India. It is responsibility of Ministry of Women and Child Development to assess the status of single mothers in India. Unfortunately Ministry of Women and Child Development and National Commission for Women are silent on this vital issue. Even National Sample Survey Office and NITI Aayog have not conducted any study on this aspect. According to few studies, single mothers are living in very pathetic condition with social, economic, cultural and psychological problems. It is need of the hour to study the number and condition of such mothers in India.

Data on Single mothers are collected and published by many countries. According to the United States Census Bureau, in 2015 $80 \%$ of single-parent families were headed by single mothers. Births to unmarried women in the United States grew from $18.4 \%$ of all live births in 1980 to $43.9 \%$ in 2014 . According to the Organization for Economic Cooperation and Development (OECD), $15 \%$ of children worldwide live in single-parent households and $85 \%$ of single-parent families are headed by single mothers. Various countries with the highest percentage of single parents are Ireland (24.3\%), New Zealand (23.7\%), and the United Kingdom (21.5\%). In 2014 approximately $24 \%$ of children in the United States lived in single-mother-headed households. In 2013 the largest number of births to unmarried women were to Black women (72\%), American Indian or Alaska Native women (66\%), and Hispanic women (53\%), compared to $29 \%$ of births to White women and $17 \%$ to Asian women.

Study found that $69 \%$ of Black youths live in single-parent households. Mothers raising children with a non resident father amount to $27.5 \%$ of all mothers in the United States, and nearly half of these families (45\%) live below the poverty threshold. Children born out of wedlock, particularly when there was not an enduring relationship between the parents, may have no knowledge of or relationship with their fathers, who may never have established legal paternity or custodial rights. Furthermore, a large proportion of divorces involve children, and following divorce the mother is often the primary care. Families headed by single mothers are especially vulnerable to material hardship, which sets the conditions for psychosocial problems and child maltreatment. Researchers have found that the more time children spend in poverty, the greater the adverse impact on their cognitive and academic achievement.

Poverty in early and middle childhood may have a greater impact on academic achievement than poverty in adolescence. The longer a single mother remains on government financial support and in poverty, the more profoundly a child's academic performance is affected. Many single mothers work, but their jobs tend to be unstable, pay minimum wage, and provide few benefits. Poorly paid jobs are correlated with increased grade repetition for the children in these families, and parental job instability is correlated with low self-esteem, depression, aggression, and school dropout among adolescents.

Families often delay seeking healthcare until the need is critical and avoid preventive services because of an inability to pay. Families headed by single mothers tend to eat fewer fruits and vegetables, and daughters in those families are more likely to be overweight or obese than daughters in families with two parents. Single mothers face enormous barriers to achieving economic self-sufficiency.

Many have low educational attainment, have limited job skills, lack transportation, and may have mental health and/ or substance abuse issues, and a large number live with recurring intimate partner violence.

When single mother's transition from welfare to work, older children spend more time unsupervised and frequently are burdened with additional household responsibilities; these situations can have negative outcomes for children. Researchers in a study of how job displacement of single mothers affects children concluded that mothers' job displacements have a negative impact 
on the educational attainment and social-psychological well-being of children in mid-childhood and adolescence.

Displacement can entail a sequence of events that can cause stress and strife in the family: job loss notification, dismissal, unemployment, job search, and lack of job offers. A critical protective factor for children living in poverty and vulnerable to psychosocial problems is the quality of their relationship with their mother. Positive relationships can be difficult to sustain in these conditions of struggle. Many single mothers receiving government assistance have been exposed to trauma, such as child sexual and physical maltreatment, sexual assault as adults, and violence.

Such trauma history is known to adversely affect all kinds of relationships. Single mothers exposed to violence are more likely to use aggressive parenting styles. Researchers have found that a father's absence from a child's life is associated with negative social, emotional, and cognitive outcomes from infancy to adolescence. A positive relationship with just one parent, whether or not the parent resides with the child, has been shown to reduce conduct problems and improve educational outcomes.

Adolescents with non resident fathers who are warm and supportive have fewer internalizing and externalizing problems, especially adolescent boys. Comparisons of countries with comprehensive welfare policies (e.g., housing, financial assistance, and medical aid) to those without indicate that those policies are a protective factor, reducing poverty and increasing overall wellbeing for children. In addition, consistent child-support payments by the non resident father contribute positively to children's educational attainment and cognitive outcomes.

It has been statistically proven that the lack of social support for single mothers causes them to spiral into depression. Over 9.5 million American families are run by one woman. This woman is most likely to have mental health issues, financial hardships, live in a low income area, and receive low levels of social support. All of these factors are taken into consideration when evaluating the mental health of single mothers. The occurrence of moderate to severe mental disability was more pronounced among single mothers at $28.7 \%$ compared to partnered mothers at $15.7 \%$.

These mental disabilities include but are not limited to anxiety and depression. Financial hardships also have an impact on the mental health of single mothers. Women, ages 15-24, were more likely to live in a low socio-economic area, have one child, and not to have completed their senior year of high school. These women reported to be in the two lowest income areas, and their mental health was much poorer than those in higher income areas. Tracie O. Afifi, Brian J. Cox, and Murray W. Enns did a study on the mental health of single mothers to answer the question, "Are there differences in the prevalence of psychiatric disorders, between married, never-married, and separated/divorced mothers?" Statistically, never married, and separated/divorced mothers had the highest regularities of drug abuse, personality disorder.

The family structure can become a trigger for mental health issues in single mothers. They are especially at risk for having higher levels of depressive symptoms. Studies from the 1970s showed that single mothers who are not financially stable are more likely to experience depression. In a more current study it was proven that financial strain was directly correlated with sky rocket levels of depression. Among low-income, single mothers, depressive symptoms may be as high as $60 \%$.

Faced with economic hardship, increasing numbers of single mothers and their children are living in alternative familial arrangements. Living with grandparents, for example, has been shown to significantly enhance the financial security of children. Researchers exploring the role of child benefits in various countries found that providing single mothers with additional child benefits (cash aid, tax credits, and tax allowances) was associated with higher levels of poverty reduction.

Risk Factors Poverty significantly increases the risk of psychosocial disadvantage and mental health problems among the children of single mothers. Dysfunctional and negative relationships also increase the risk of negative outcomes for children. Job instability and unemployment among single mothers increase children's risk for low self-esteem, depression, and aggression. Children deprived of a father are at greater risk for drug and alcohol abuse, poor educational performance, adolescent pregnancy, criminal activity, poverty, and homelessness. They are more likely to commit suicide than are those who grow up in a home with both their mother and father.

Supporting single mothers toward economic self-efficiency and lifting the burden of poverty is one of the best ways to ensure the well-being of children and their successful transition to adulthood. Education and job training for these women is critical, as is parenting skills training. Single mothers by mastering any skill will help them generate a livelihood. The single mothers should be linked with the existing job/work oriented vocational training programs for women implemented by NGOs/companies or vocational training programs especially focusing on single mothers should be initiated to be able to generate livelihood opportunities for single mothers. 
Creative Commons Attribution 4.0 International License

For possible submissions Click Here

Submit Article

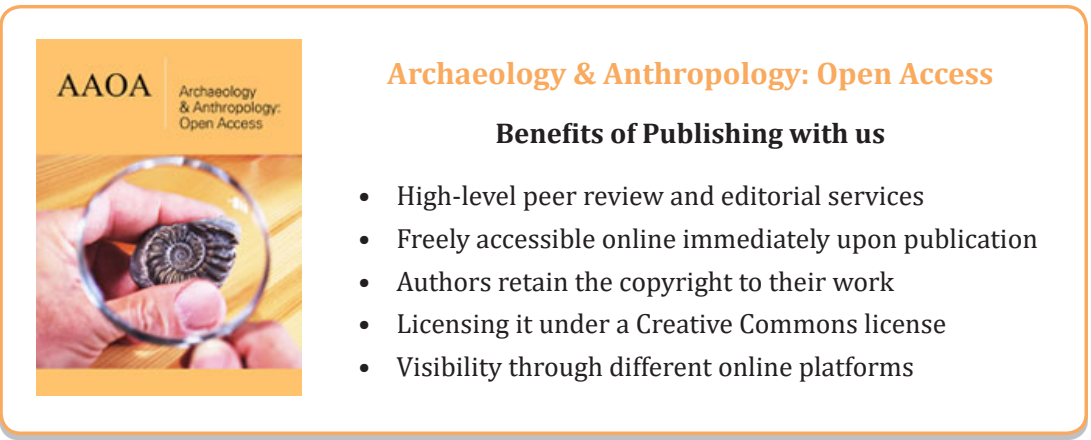

